\title{
An unusual case of aortic rupture after deployment of a bare stent in the treatment of aortic dissection in a patient with giant-cell arteritis
}

\author{
Pawel Rynio, Arkadiusz Kazimierczak, Piotr Gutowski, Miloslaw Cnotliwy \\ Department of Vascular Surgery, Pomeranian Medical University, Szczecin, Poland
}

Videosurgery Miniinv 2017; 12 (2): 194-198

DOI: https://doi.org/10.5114/wiitm.2017.67677

\begin{abstract}
Giant-cell arteritis is associated with a higher risk of aortic aneurysm and aortic dissection formation. We present a women with aortic dissection type B treated with a stent graft and bare-metal stent implantation. After the stent deployment we noticed aortic rupture, which was successfully treated with implantation of an additional stent graft. This report highlights the difficulty of endovascular therapy in patients with giant-cell arteritis. We have to bear in mind that chronic inflammation of the aorta leads to a more fragile aortic wall than normal. We recommend the use of a stent graft over a bare-metal stent and gentle use of a balloon catheter.
\end{abstract}

Key words: stent graft, endovascular treatment, aortic dissection, giant-cell arteritis, aortic rupture, petticoat.

\section{Introduction}

Giant-cell arteritis (GCA) is associated with a higher incidence of aortic dissection (AD) [1-3]. However, most cases of AD have an etiology other than GCA. One of the recommended methods of treatment of $A D$ is the coverage of the entry tear with a stent graft [4]. Some vascular surgeons have expanded this method by the use of an additional bare stent deployed distally [5-7]. This report highlights the difficulty of such therapy in a patient with GCA.

\section{Case report}

In September 2016, a 70-year-old woman with GCA was admitted for treatment of a type B aortic dissection in the thoracic and abdominal aorta. Her past medical history was significant for polymyalgia rheumatica, a fatty liver, hypertension, and cirrhosis of the right kidney on a vascular background. She was diagnosed with giant-cell arteritis 12 years ago. At the beginning the disease had a self-limited course and she was only on non-steroid anti-inflammatory drugs. For the last 7 years she had had aortic complications, thickening of the aortic wall, and stenosis of the aortic arch branches, renal arteries and common iliac arteries. The wall in the ascending aorta was approximately $0.98 \mathrm{~cm}$ and $0.44 \mathrm{~cm}$ in the abdominal aorta. Regular courses of steroids and cyclophosphamide were instituted to reduce the inflammatory process of the aorta, but failed to improve the stenosis in the aortic branches. Furthermore, in subsequent years cirrhosis of the right kidney was found. Some 5 months ago control computed tomography angiography (CTA) revealed thoracoabdominal dissection type B. Although no symptoms in the chest and abdominal region were found, the patient nonetheless developed progressive intermittent claudication, categorized as stage 3 on the Rutherford scale. The false lumen in the right lateroposterior region was found to have an entry 
tear in the lower thoracic segment, a re-entry tear in the vicinity of the celiac trunk and another re-entry approximately $3 \mathrm{~cm}$ above the aortic bifurcation. The false lumen was supplied by a posterior intercostal artery in the thoracic area. No part of the major vessel was supplied by a false lumen. The true lumen was stenosed to $6 \mathrm{~mm}$ about $3 \mathrm{~cm}$ above the aortic bifurcation (Photo 1).

The procedure was planned to cover the entry tear with a stent graft in the thoracic region (Valiant Captiva, Medtronic, USA) and a bare-metal stent (Sinus-XL Stent, Optimed, Germany) in the abdominal

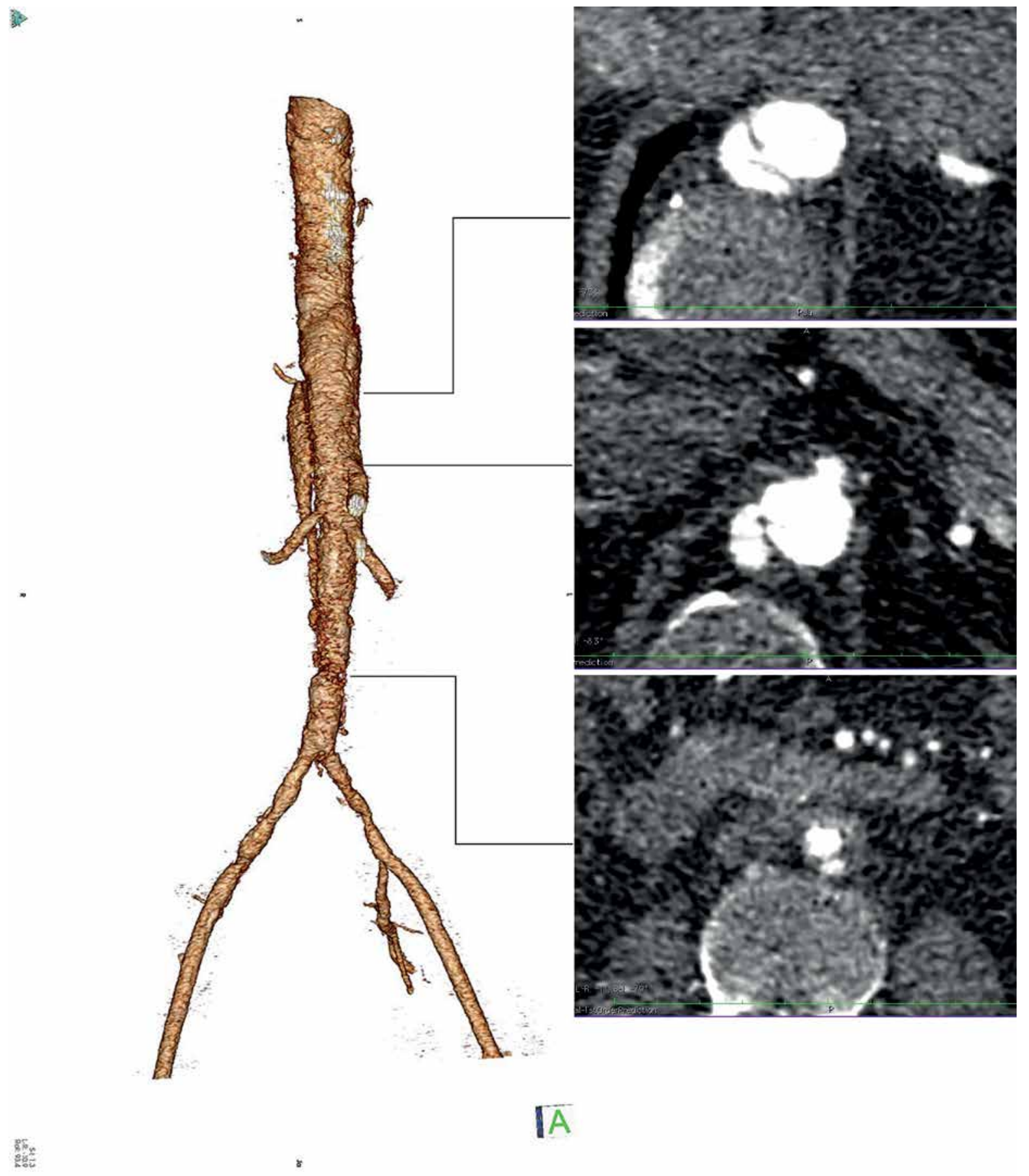

Photo 1. 3D reconstruction showing patent false lumen 
region to expand the true lumen and compress the false lumen. Afterwards a stent was deployed and expanded with a balloon catheter (Reliant, Medtronic, USA) to restore the whole lumen. However, complications arose when an anesthesiologist reported a sudden drop in the patient's blood pressure. Control angiography was then performed and an aortic rupture was revealed in the middle between the renal ostia and the abdominal aortic bifurcation (Photo 2). It was decided to implant another stent graft inside the previous mentioned stent. An iliac extension was used for this purpose (Endurant II, Medtronic, USA). Although a residual bruise was detected following this process (Photo 3), the blood pressure subsequently normalized, so a decision not to perform additional procedures was reached. After closure of the wound, $10 \mathrm{mg}$ of protamine sulfate was given to efficiently reverse (based on ACT) the effect of 3000 units of heparin which was administered at the beginning of the procedure.

The patient was admitted to the intensive care unit for a duration of 3 days. After 7 days of hospitalization she was discharged without any other problems.

\section{Discussion}

Giant-cell arteritis is chronic inflammation of medium and large-sized vessels containing elastic

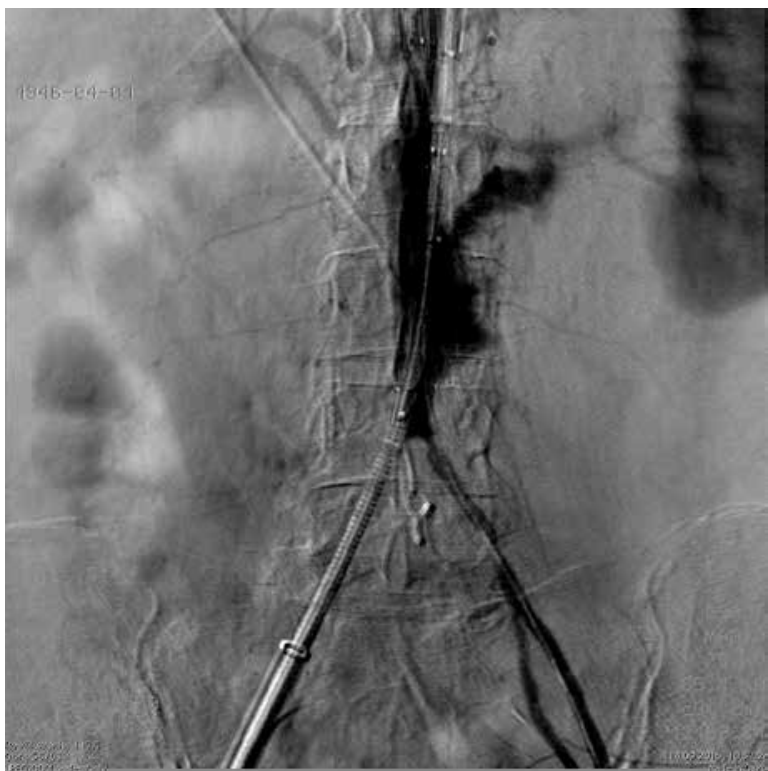

Photo 2. Angiography after bare stent deployment showing aortic rupture fibers. The most often affected vessel is the temporal artery. It is for this reason that GCA is sometimes called temporal arteritis. Inflammation of the intracranial arteries seldom occurs [8]. The incidence is the highest in Scandinavian countries and in people of Scandinavian descent and is approximately 20-30 per 100000 persons aged 50 years and older $[9,10]$. Women are affected 2-3 times more often than men $[11,12]$. Typically patients are over 50 years of age and morbidity increases with age, reaching a peak in octogenarians [11, 12].

In contrast, non-GCA AD is more often found in men, with a men-to-women ratio of $4: 1$ [13]. Hypertension and age are the main risk factors [14]. The incidence is about 2.9-3.5 per 100000 person-years, with the peak between 50 and 70 years of age [14].

A patient with GCA is 17.3 times more likely to develop a thoracic aortic aneurysm and 2.3 times more likely to develop an abdominal aneurysm [1]. Other studies suggest a 9.5-18\% chance of developing aortic aneurysm or dissection [2, 3]. Twenty-five - forty percent of aortic dissections will develop into an aneurysm $[15,16]$. Factors associated with aneurysmal progression include poorly controlled hypertension, patent false lumen and an aorta diameter of $4 \mathrm{~cm}$ or more [17].

The pathogenesis of GCA is complex and not fully understood. However, the inflammation starts from activated dendritic cells in the adventitia,

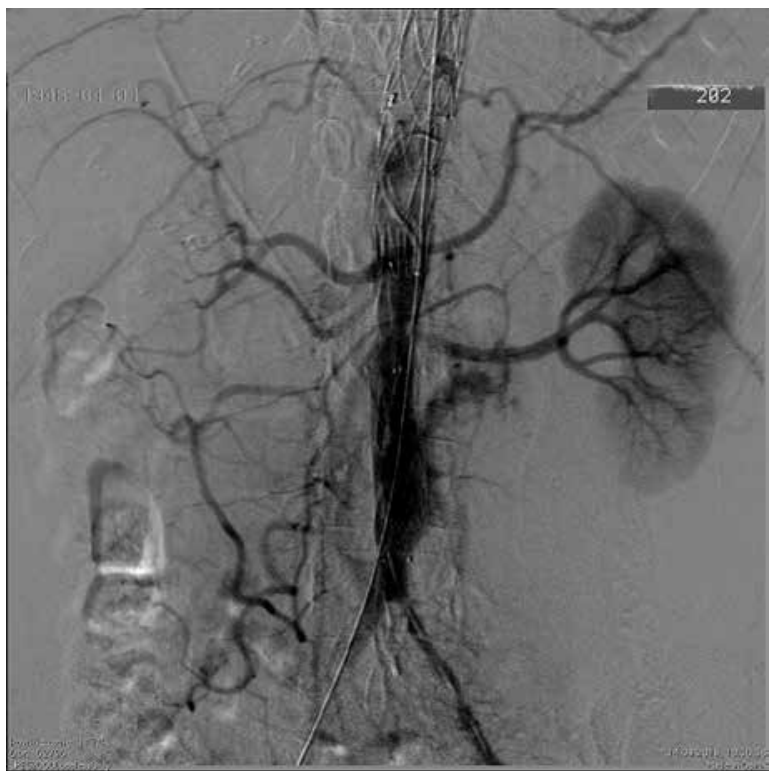

Photo 3. Angiography showing residual bruise after additional stent graft implantation 
which attract CD4 $\mathrm{T}$ lymphocytes. The release of cytokines including interferon $\gamma$ brings monocytes to the place, which transform into multinucleated giant cells - the hallmark of GCA. Macrophages produce matrix metalloproteinases and reactive oxygen species which damage the media [18-21]. Thus the aortic wall is weakened and impaired due to hypertension and may lead to aortic dissection. In such a case the fragility of the wall could contribute to aortic rupture after stent expansion. Additionally, although the chronic administration of steroids may be responsible for the weakness of the aortic wall [22-24] and could play a role, steroids are nevertheless needed in complicated GCA because they inhibit the inflammation. The most common localization of the entry tear in type $B$ $A D$ is in the vicinity of the left subclavian artery $[25,26]$. It is caused by considerable $\mathrm{dP} / \mathrm{dt}$ pressure fluctuations in that region. Therefore, the mechanical force cleaves to the layers of the aortic wall. When, as in the reported case, the entry tear was situated at a greater distance from the left subclavian artery in the same region, lower $\mathrm{dP} / \mathrm{dt}$ pressure fluctuations were noticed. This suggests that the fragile wall contributed more to $A D$ than mechanical stress.

The combination of stent grafting with bare-metal stenting in AD was first proposed by Mossop et al. $[5,6]$. The idea is to cover the entry tear with a stent graft and then, distally, expand the true lumen with a bare stent promoting false lumen thrombosis. The use of a bare stent also has the advantage of protecting the vessels' ostia from occlusion, thus preserving the inflow. The concept was named PETTICOAT, an abbreviation of Provisional ExTension To Induce COmplete ATtachment.

Mossop et al. in their subsequent studies proved the safety of bare stents in AD. They did not report aortic rupture as a complication of bare-metal stenting in $\operatorname{AD}[5,6]$. Other authors encountered one aortic rupture [7]. However, the rupture was located distally to the distal end of the bare stent, and it concerned only the false lumen, with the intimal flap between both lumens still intact.

Usually aortic ruptures, if and when they happen, following a subsequent endovascular aortic repair (EVAR), are due to endoleaks which cause constant pressurization of the aortic wall. This results in aneurysmal growth and eventually rupture [27-31]. This process is extended in time. By con- trast, in the described case the rupture occurred immediately.

The amount of stent oversizing may also play a role. Most instructions for use (IFU) advise about $10 \%$. We used an $18 \mathrm{~mm}$ stent so oversizing was approximately $12 \%$ in the upper part of the aorta, but the aorta decreased in size in the lower part region where the focal stenosis $(6 \mathrm{~mm})$ was located, resulting in considerable oversizing. This oversizing in the lower part of the aorta does not appear to be responsible for the rupture, because the rupture was located $2 \mathrm{~cm}$ above the region that had the greatest stenosis. Anyway, we could not calculate the stent size according to stenosed area, because the stent would be free floating in the upper part of the aorta. It may also be the case that the excessive expansion caused by a balloon catheter also contributed to the aortic rupture. Nevertheless, a low pressure balloon catheter is considered part of a more reliable procedure since it is safer. Despite the fact that some authors do not advise post-dilatation in AD [32], we nonetheless perform it routinely in non-GCA AD, and we have never observed aortic rupture before. Postdilatation compresses the false lumen, which limits the inflow from re-entries, thus preventing its further expansion and compression of the true lumen. Fanelli et al. observed increased aortic remodeling after postdilatation in AD [33]. A similar effect was obtained by Kölbel et al., who constructed a stent graft designed to treat $A D$ which has a unique shape, a hump in the midsection that obstructs the false lumen and prevents a continuous false lumen perfusion [34].

To cover the rupture we used an additional stent graft. In our opinion a covered stent should be the first line strategy in patients with GCA and aortic dissection. Even if endovascular treatment causes a rupture, it will automatically be covered by a stent graft and it will prevent extravasation of the blood.

\section{Conclusions}

In patients with GCA and aortic dissection the aortic wall is more fragile than in patients with nonGCA aortic dissection. Therefore, careful expansion of endovascular devices is recommended. Furthermore, we recommend the use of stent grafts over bare stents.

\section{Conflict of interest}

The authors declare no conflict of interest. 


\section{References}

1. Evans JM, O'Fallon WM, Hunder GG. Increased incidence of aortic aneurysm and dissection in giant cell (temporal) arteritis. Ann Intern Med 1995; 122: 502-7.

2. NuenninghoffDM, Hunder GG, Christianson TJH, et al. Incidence and predictors of large-artery complication (aortic aneurysm, aortic dissection, and/or large-artery stenosis) in patients with giant cell arteritis. Arthritis Rheum 2003; 48: 3522-31.

3. González-Gay MA, García-Porrua C, Piñeiro A, et al. Aortic aneurysm and dissection in patients with biopsy-proven giant cell arteritis from northwestern Spain. A population-based study. Medicine 2004; 83: 335-41.

4. Dake MD, Kato N, Mitchell RS, et al. Endovascular stent-graft placement for the treatment of acute aortic dissection. N Engl J Med 1999; 340: 1546-52.

5. Mossop P, McLachlan CS, Amukotuwa SA, et al. Staged endovascular treatment for complicated type B aortic dissection. Nat Clin Pract Cardiovasc Med 2005; 2: 316-22.

6. Mossop P, Nixon I. Staged endovascular management of complicated type B aortic dissection. In Proceedings of the International Endovascular Symposium 2004; 24.

7. He H, Yao K, Nie WP, et al. Modified Petticoat technique with pre-placement of a distal bare stent improves early aortic remodeling after complicated acute Stanford type B aortic dissection. Eur J Vasc Endovasc Surg 2015; 50: 450-9.

8. Warrington KJ, Matteson EL. Management guidelines and outcome measures in giant cell arteritis (GCA). Clin Exp Rheumatol 2007; 25: 137-41.

9. Salvarani C, Crowson CS, O'Fallon WM, et al. Reappraisal of the epidemiology of giant cell arteritis in Olmsted County, Minnesota, over a fifty-year period. Arthritis Rheum 2004; 51: 264-8.

10. Kermani TA, Schäfer VS, Crowson CS, et al. Increase in age at onset of giant cell arteritis: a population-based study. Ann Rheum Dis 2010; 69: 780-1.

11. Dejaco C, Duftner C, Buttgereit F, et al. The spectrum of giant cell arteritis and polymyalgia rheumatica: revisiting the concept of the disease. Rheumatology (Oxford) 2016 Aug 1. pii: kew273 [Epub ahead of print].

12. Nordborg C, Nordborg E, Petursdottir V. Giant cell arteritis. Epidemiology, etiology and pathogenesis. APMIS 2000; 108: 713-24.

13. Januzzi JL, Isselbacher EM, Fattori R, et al. Characterizing the young patient with aortic dissection: results from the International Registry of Aortic Dissection (IRAD). J Am Coll Cardiol 2010; 43: 665-9.

14. Hagan PG, Nienaber CA, Isselbacher EM, et al. The International Registry of Acute Aortic Dissection (IRAD): new insights into an old disease. JAMA 2010; 283: 897-903.

15. Tolenaar JL, van Keulen SA, Jonker FH, et al. Morphologic predictors of aortic dilatation in type B aortic dissection. J Vasc Surg 2013; 58: 1220-5

16. Sueyoshi E, Sakamoto I, Uetani M. Growth rate of affected aorta in patients with type B partially closed aortic dissection. Ann Thorac Surg 2009; 88: 1251-7.

17. Sueyoshi E, Sakamoto I, Hayashi K, et al. Growth rate of aortic diameter in patients with type B aortic dissection during the chronic phase. Circulation 2004; 110 (Suppl. 1): ॥256-61.
18. Weyand CM, Younge BR, Goronzy JJ, et al. IFN-gamma and IL-17: the two faces of T-cell pathology in giant cell arteritis. Curr Opin Rheumatol 2004; 23: 43-9.

19. Weyand CM, Ma-Krupa W, Pryshchep O, et al. Vascular dendritic cells in giant cell arteritis. Ann N Y Acad Sci 2004; 1062: 195-208.

20. Weyand CM, Ma-Krupa W, Goronzy JJ, et al. Immunopathways in giant cell arteritis and polymyalgia rheumatica. Autoimmun Rev 2004; 3: 46-53.

21. Watanabe R, Hosgur E, Zhang $\mathrm{H}$, et al. Pro-inflammatory and anti-inflammatory $\mathrm{T}$ cells in giant cell arteritis. Joint Bone Spine 2016 Sep 20. pii: S1297-319X(16)30124-5. doi: 10.1016/j. jbspin.2016.07.005 [Epub ahead of print].

22. Ohara N, Miyata T, Sato O, et al. Aortic aneurysm in patients with autoimmune diseases treated with corticosteroids. Int Angiol 2000; 19: 270-5.

23. Arul Rajamurugan PS, Panchapakesa Rajendran C, Rukmangatharajan S, et al. Aortic dissection in a case of systemic lupus erythematosus. Lupus 2007; 16: 1001-3.

24. Hedges AR, Bentley PG. Resection of inflammatory aneurysm after steroid therapy. Br J Surg 1986; 73: 374.

25. Hirst AE, Johns VJ Jr, Kime SW Jr, et al. Dissecting aneurysm of the aorta: a review of 505 cases. Medicine 1958; 37: 217-9.

26. Wheat MW Jr. Acute dissection of the aorta. Cardiovasc Clin 1987; 17: 241-62.

27. Stather PW, Wild JB, Sayers RD, et al. Endovascular aortic aneurysm repair in patients with hostile neck anatomy. J Endovasc Ther 2013; 20: 623-37.

28. Cao P, De Rango P, Verzini F, et al. Endoleak after endovascular aortic repair: classification, diagnosis and management following endovascular thoracic and abdominal aortic repair. J Cardiovasc Surg 2010; 51: 53-69.

29. Wojtaszek M, Wnuk E, Maciag R, et al. Improving the results of transarterial embolization of type 2 endoleaks with the embolic polymer Onyx. Videosurgery Miniinv 2016; 11: 259-67.

30. Wachal K, Szmyt K, Oszkinis G. Diagnosis and treatment of a patient with type IV endoleak as a late complication after endovascular aneurysm repair. Videosurgery Miniinv 2014; 9 : 667-70.

31. Synowiec T, Warot M, Burchard P, et al. All dangerous types of endoleaks after endovascular aneurysm repair in a single patient. Videosurgery Miniinv 2015; 10: 290-4.

32. Kpodonu J, Preventza O, Ramaiah VG, et al. Retrograde type A dissection after endovascular stenting of the descending thoracic aorta. Is the risk real? Eur J Cardiothoracic Surg 2008; 33: 1014-8.

33. Fanelli F, Cannavale A, O'Sullivan GJ, et al. Endovascular repair of acute and chronic aortic type B dissections. JACC CardiovasC Interv 2016; 9: 183-91.

34. Kölbel T, Carpenter SW, Lohrenz C, et al. Addressing persistent false lumen flow in chronic aortic dissection: the Knickerbocker technique. J Endovasc Ther 2014; 21: 117-22.

Received: 21.11.2016, accepted: 26.03.2017. 